\title{
Diz ve kalçada antibiyotikli çimentodan spacer hazırlama tekniği
}

\author{
Spacer preparation technique with cement in the knee and hip
}

\author{
Gökhan Kaynak, Suat Ulutaş \\ İstanbul Üniversitesi-Cerrahpaşa, Cerrahpaşa Tıp Fakültesi, Ortopedi ve Travmatoloji Anabilim Dalı, İstanbul
}

\begin{abstract}
Diz ve kalça protezi ameliyatlarının sayısı her geçen yıl artmakta, enfeksiyon nedeni ile revizyon ameliyatı yapılan hastaların sayısı da bu artışa eşlik etmektedir. Protez çevresi enfeksiyonları erken veya geç dönemde gerçekleşebilir. Periprostetik enfeksiyonlarda, iki aşamalı revizyon altın standart tedavi olarak kabul edilmektedir. İlk aşamada protez çıkarılmalıdır. Daha sonra irrigasyon yapılmalı, geniş debridmanlarla ölü dokular temizlenmeli ve çıkarılan protezden kaynaklanan boşluk geçici olarak antibiyotikli çimento spacer ile doldurulmalıdır. Kullanılan çimento spacer'lar statik veya dinamik olabilir. Bunların piyasada çeşitli hazır formları bulunmakla beraber, sadece belirli antibiyotikleri içermeleri ve yeterli doz içermemeleri nedeni ile sıklıkla cerrahlar tarafindan yapılan custommade spacer'lar tercih edilmektedir. İkinci aşamada ise, kalıcı protezler yerleştirilmeden önce, çimento spacer çıkarılmalı, irrigasyon ve debridman tekrarlanmalıdır. Bu yazıda, iki aşamalı revizyon cerrahisi kararı verilen bir olguda kullanılan çimento spacer'ın hazırlanma aşamaları ayrıntılarıyla anlatılmıştır.
\end{abstract}

Anahtar sözcükler: protez çevresi enfeksiyonları; iki aşamalı revizyon cerrahisi; antibiyotik yüklü çimento spacer

\begin{abstract}
The number of knee and hip surgeries are increasing every year; the number of patients undergoing revision surgery because of infection also accompanies this increase. Periprosthetic joint infection can occur early or late. For the treatment of periprosthetic joint infection, two-stage revision surgery is considered as the gold standard. At the first stage, the prosthesis is removed. Then comes irrigation, debridement of nonviable tissues, and filling of space caused by the prosthesis with antibiotic-loaded cement spacer temporarily. Cement spacers can be static or dynamic. Various pre-formed cement spacers are available on the market, but custom-made ones are often preferred by the surgeons because pre-formed spacers contain only certain kinds of antibiotics with insufficient doses. At the second stage before permanent prosthesis is placed, cement spacer should be removed, irrigation and debridement be repeated. This article describes in detail the stages of preparation of the cement spacer used in two-stage revision surgery.
\end{abstract}

Key words: periprosthetic joint infection; two stage revision surgery; antibiotic loaded cement spacer
T otal diz ve kalça artroplastisi, son evre gonartroz ve koksartroz hastalarında etkili tedavi yöntemidir. Yaşlı nüfustaki artış ile birlikte, diz ve kalça protezi olguları her yıl giderek artmaktadır. Protez çevresi enfeksiyonları, protez ameliyatlarından sonraki başarısızlığın en sık nedenlerinden biridir. Yapılan çalışmalar, total diz protezi operasyonu sonrası $\% 0,86$ ile $\% 1,55$, total kalça protezi sonrası ise \%0,3 ile \%1,63 arasında protez çevresi enfeksiyonu gelişebileceğini göstermiştir. ${ }^{[1-4]}$

Protez çevresi enfeksiyonlarında yalnız antibiyotik tedavisi çoğu hastada yeterli olmamaktadır. Erken enfeksiyonlarda debridman, yıkama (irrigasyon) ve insert değişimi, geç enfeksiyonlarda tek aşamaIı veya iki aşamalı revizyon cerrahisi, diğer tedavi seçeneklerinin mümkün olmadığı hastalarda ise ampütasyon, gerekli olabilen tedavi seçenekleridir.

Protez çevresi enfeksiyonlarında genellikle tek veya çift aşamalı cerrahi gerekmektedir. Son yapılan çalışmalarda iki aşamalı cerrahi tedavinin altın standart tedavi olabileceği tartışılmaktadır. İki aşamalı revizyon cerrahisi, ilk olarak 1983 yılında Insall ve ark. tarafından tanımlanmıştır. ${ }^{[5]}$ Bu teknik; ilk aşamada mevcut protezin çıkarılması, ölü ve enfekte dokulara yönelik geniş debridman yapılması, medüller kanalın temizlenmesinin ardından ortaya çıkan eklem boşluğuna, hazır veya cerrah tarafından hazırlanan antibiyotikli çimento spacer'ın yerleştirilmesini içermektedir. Operasyon sonrası, duyarlı organizmaya göre antibiyotik tedavisine başlanması gerekir. İkinci aşama ise

- İletişim adresi: Doç. Dr. Gökhan Kaynak, İstanbul Üniversitesi-Cerrahpaşa, Cerrahpaşa Tıp Fakültesi, Cerrahpaşa, Fatih, İstanbul Tel: 0212 - 4143000 e-posta: Kaynak95@hotmail.com

- Geliș tarihi: 24 Ocak $2019 \quad$ Kabul tarihi: 24 Ocak 2019 
mevcut antibiyotikli çimento spacer'ın çıkarılması ve tekrar debridman yapılarak revizyon protezlerinin yerleştirilmesini kapsar.

\section{ANTIBIYOTIKLI ÇIMENTO SPACER HAZIRLANMASI VE KULLANIMI}

Antibiyotikli çimento spacer'ın amacı; eklem aralığını korumak, kontraktürü önlemek ve bölgesel olarak yüksek dozda antibiyotik salınımı sağlamaktır. Spacer'lar iki farklı formda kullanılabilir; statik veya dinamik. Statik spacer'ların kullanımı geçici artrodez oluşturmakla birlikte, temel amacı eklem stabilizasyonunu ve ikinci aşamada kullanılacak protezler için gerekli boşluğu sağlamaktır. Statik spacer'ların kullanıldığı durumda, eklemde hareket olanağı yoktur. Dinamik spacer'da ise eklem hareketi sağlanarak, daha iyi fonksiyonel durum, daha fazla eklem hareket açıklığı ve uygun ekstremite boy uzunluğu elde edilebilmektedir. Statik spacer'lar genel olarak, kemik kaybı fazla ve aynı zamanda kollateral bağ kaybı da olan hastalarda önerilir. ${ }^{[6]}$

Piyasada hazır bulunan bir çimento spacer, hem standart birkaç tür antibiyotikten birini içermesi hem de bu antibiyotiğin düşük dozda olması nedeni ile, enfeksiyonu tedavi etmede yetersiz kalmaktadır. Çimento spacer'da kullanılan antibiyotikler; termodinamik olarak stabil olmalı, suda çözünmeli, bakterisidal olmalı, uygun zamanda uygun miktarda antibiyotik salınımı sağlamalı, minimal bölgesel inflamasyona neden olmalı ve en önemlisi kültüre duyarlı olmalıdır. ${ }^{[7]}$ Genel olarak bu özellikleri taşıyan antibiyotikler; teikoplanin, amikasin, ampisilin, siprofloksasin,

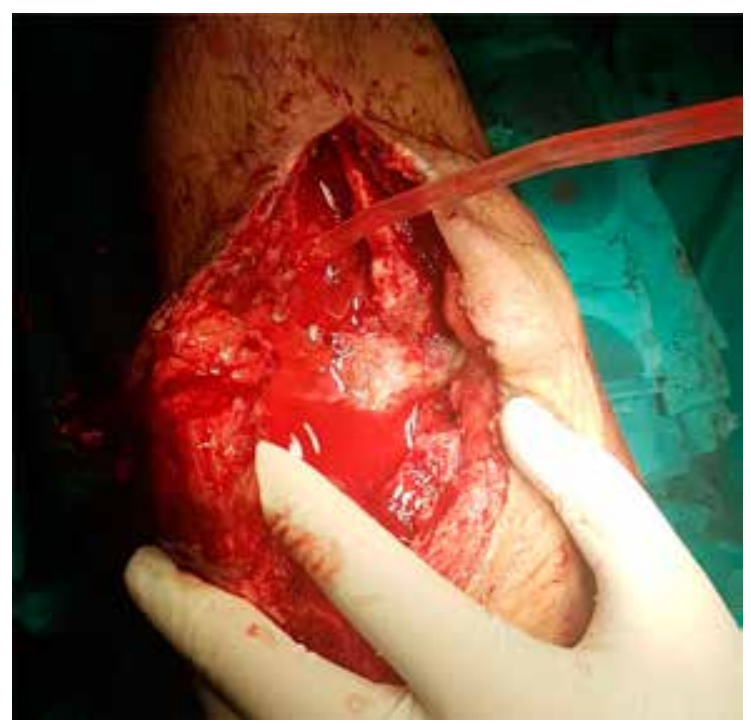

Şekil 1. Femurun debride edilerek ve yıkanarak hazırlanması. gentamisin ve vankomisindir. ${ }^{[7]}$ Çimento spacer'a eklenecek antibiyotik miktarı, eğer biyomekanik stabilite önemli değilse, total çimento ağırlığını yüzde 10 'una kadar olabilir (40 g standart çimentoya en fazla $4 \mathrm{~g}$ antibiyotik) ama sistemik toksisite ve yan etkiler konusunda dikkatli olunmalıdır. ${ }^{[6]}$ ikinci aşama kullanılacak çimentoya eklenecek antibiyotik miktarı, biyomekanik özelliği bozmaması için yüzde 10'dan fazla olmamalıdır. ${ }^{[8]}$

\section{Olgu}

Altmış dört yaşında erkek hasta. Başka bir kurumda sol total diz artroplastisi yapılan, travma sonrası kliniğimize ağrı şikâyeti ile başvuran hastada; alınan diz aspirasyon örneklerinde üreme olmaması üzerine; sol total diz artroplastisinde aseptik gevşeme tanısı konularak, Şubat 2018'de tek aşamalı revizyon total diz artroplastisi ameliyatı yapıldı. Ameliyat sonrası takiplerde, hastada yara yeri problemi gelişmesi ve fistülize akıntı olması nedeni ile Mayıs 2018'de protez ekstraksiyonu ve çimento spacer uygulamasına karar verildi. Operasyon sırasında; protezin çıkarılması, eski çimentonun kazınması, ölü dokuların çıkarılması ve debridman sonrası hastada geniş kemik doku kaybı olduğu görüldü. Mevcut defektin hazır çimento spacer ile doldurulamayacağına karar verilerek, Spacer K / Vancogenx-Space TECREX ${ }^{\circledR}$ marka hazır eklemli çimento spacer'a Zimmer Hi-Fatigue G Bone Cement ${ }^{\circledR} 40$ gr içine 4 gr vankomisin metal tas içinde metal kaşık yardımı ile karıştırılarak "custom-made çimento spacer" hazırlandı ve eklem aralığı dolduruldu (Şekil 1-8). Hastanın diz hareketleri kısıtlanarak diz ekstansiyon breysi uygulandı.

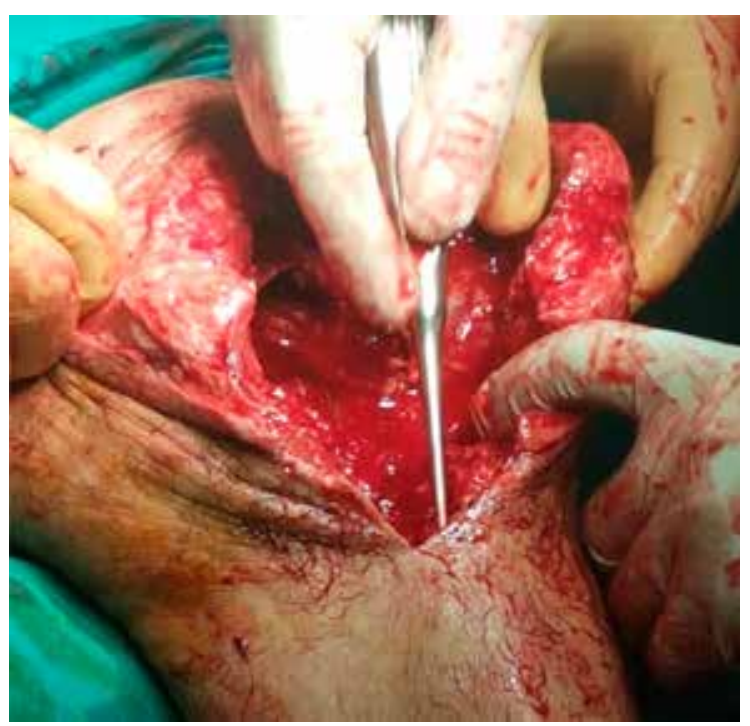

Şekil 2. Tibianın debride edilerek ve yıkanarak hazırlanması. 


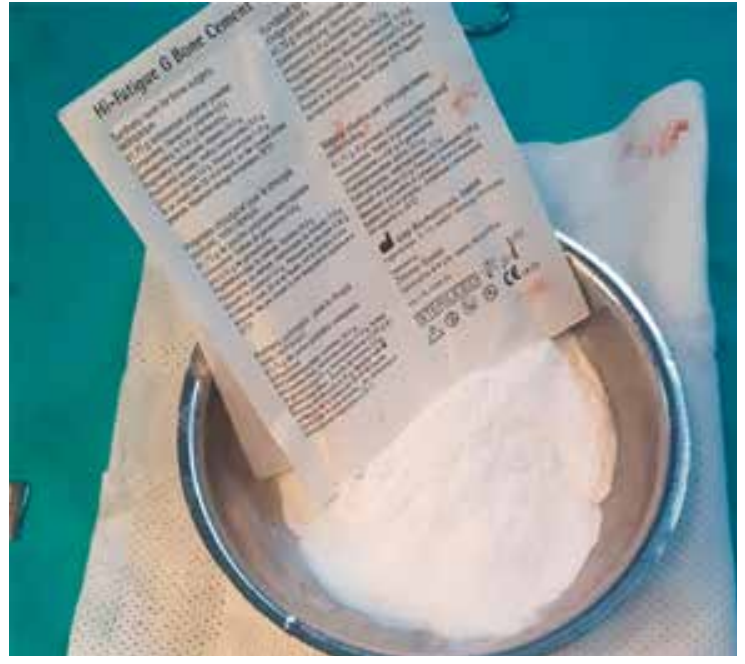

Şekil 3. Antibiyotikli çimentonun hazırlanması.

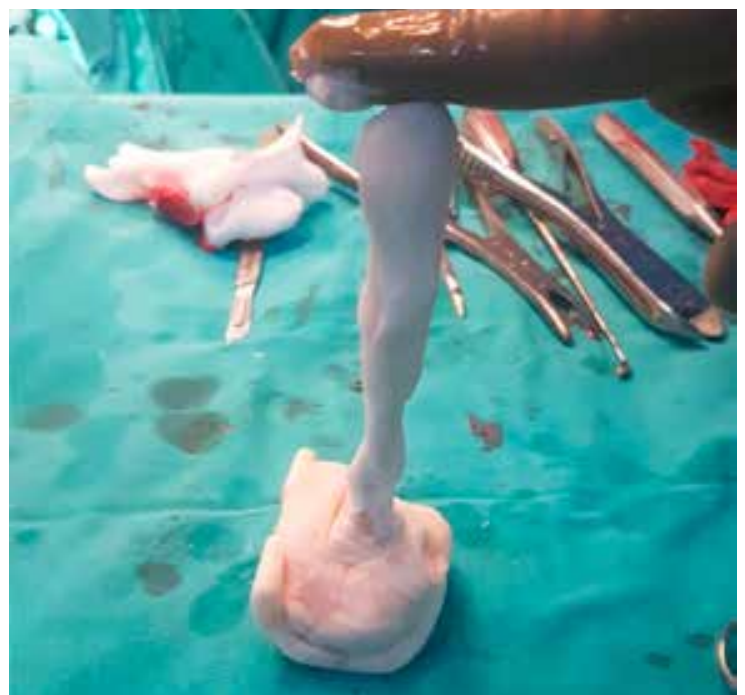

Şekil 5. Femur tarafının son hali.

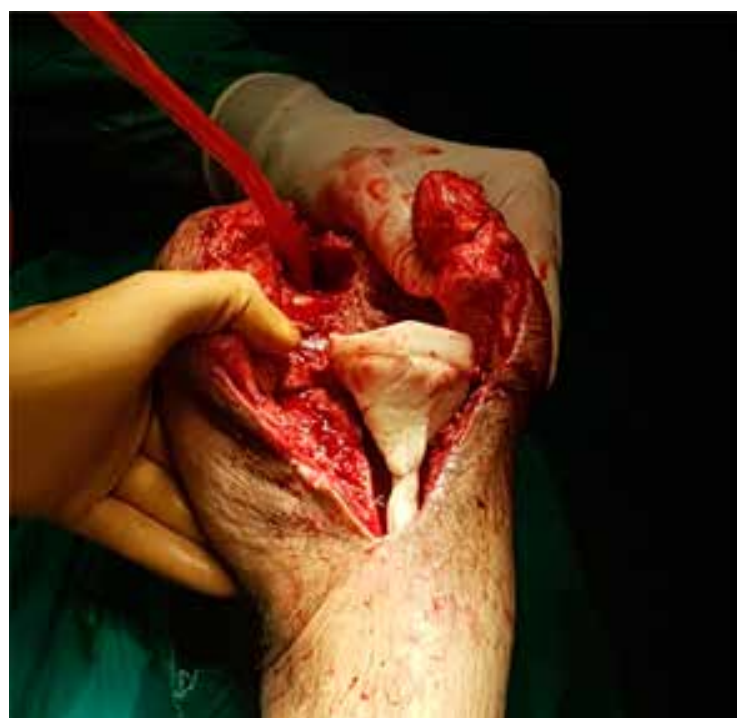

Şekil 7. Tibial tarafın yerleştirilmesi.

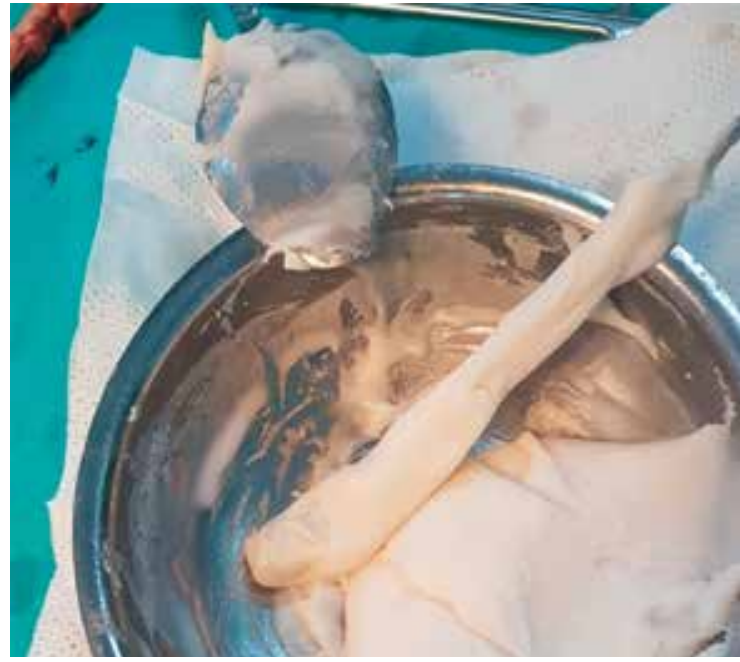

Şekil 4. Metal tas ve kaşık yardımı ile spacer'ın hazırlanması.

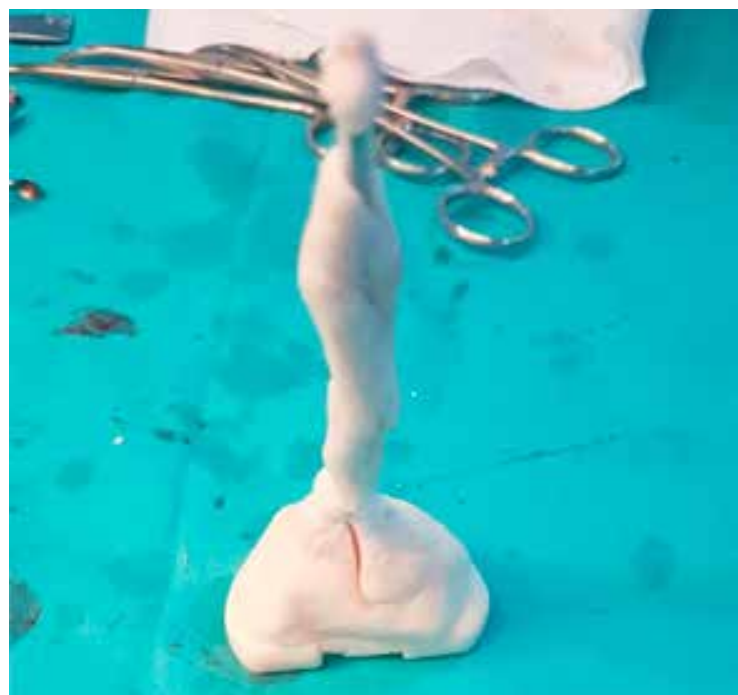

Şekil 6. Tibial tarafının son hali.

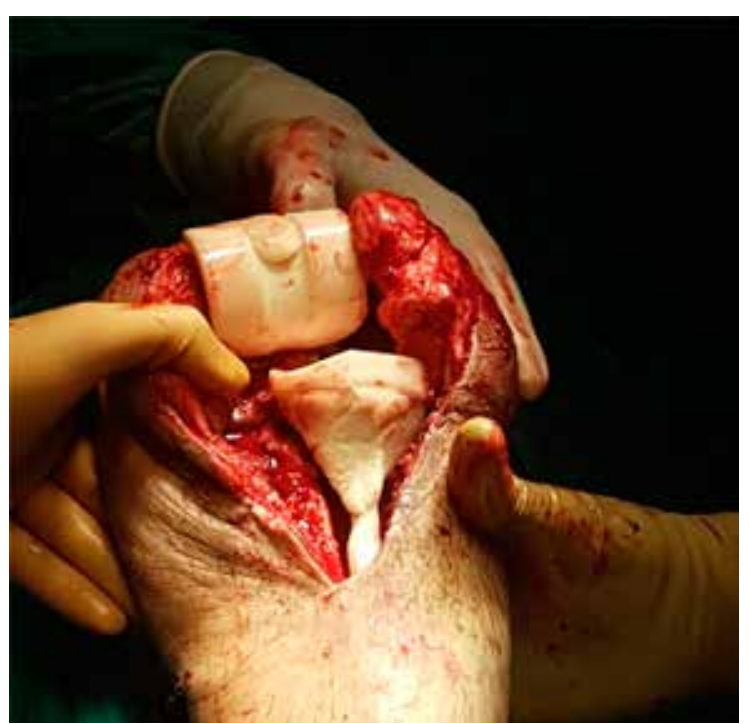

Şekil 8. Femoral tarafın yerleştirilmesi. 


\section{KAYNAKLAR}

1. Ong KL, Kurtz SM, Lau E, Bozic KJ, Berry DJ, Parvizi J. Prosthetic joint infection risk after total hip arthroplasty in the Medicare population. J Arthroplasty 2009;24(6):105-9. Crossref

2. Phillips JE, Crane TP, Noy M, Elliott TSJ, Grimer RJ. The incidence of deep prosthetic infections in a specialist orthopaedic hospital. J Bone Joint Surg Br 2006;88-B(7):9438. Crossref

3. Pulido L, Ghanem E, Joshi A, Purtill JJ, Parvizi J. Periprosthetic joint infection: the incidence, timing, and predisposing factors. Clin Orthop Relat Res 2008;466:1710-5. Crossref

4. Kurtz SM, Ong KL, Lau E, Bozic KJ, Berry D, Parvizi J. Prosthetic joint infection risk after TKA in the Medicare population. Clin Orthop Relat Res 2010;468:52-6. Crossref
5. Insall JN, Thompson FM, Brause BD. Twostage reimplantation for the salvage of infected total knee arthroplasty. J Bone Joint Surg Am 1983;65(8):1087-98. Crossref

6. Gehrke $\mathrm{T}$, Alijanipour $\mathrm{P}$, Parvizi J. The management of an infected total knee arthroplasty. Bone Joint J 2015;97-B(10 Suppl A):20-9. Crossref

7. Kuzyk PR, Dhotar HS, Sternheim A, Gross AE, Safir O, Backstein D. Twostage revision arthroplasty for management of chronic periprosthetic hip and knee infection: techniques, controversies, and outcomes. J Am Acad Orthop Surg 2014;22(3):153-64. Crossref

8. Wahlig $\mathrm{H}$, Dingeldein $\mathrm{E}$, Buchholz HW, Buchholz $\mathrm{M}$, Bachmann F. Pharmacokinetic study of gentamicin loaded cement in total hip replacements. Comparative effects of varying dosage. J Bone Joint Surg Br 1984;66-B(2):175-9. Crossref 